\title{
Walkability in residential neighbourhoods: Themes and principles revisited
}

\begin{abstract}
The article sets to examine broader theoretical scope of walkability, and research efforts dealing with measurement of walkable environments, with a specific aim to distil and translate walkability as a measure to walkability as a design principles toolbox of interventions and items. Overarching walkability themes are in due course branched out into more operational walkability principles and broken into further constituents of implementable interventions and items, derived from research and theoretical contributions of numerous authors. The focus lies on newly designed residential neighbourhoods, which we also demonstrate and extensively illustrate on an example of a proposed neighbourhood. Emphasis is placed on an integrative approach, where the holistic aspects of walkability - dealing with all of them at once - and its multidimensionality - intertwinement and co-dependency - are integral parts and built into the design, implementation, and use.
\end{abstract}

Keywords: walkability principles, key walkability themes, urban design, urban planning, residential neighbourhood, interventions, walkable urban environments

\section{Introduction}

Walkability has been present in debates and practices ever since it was popularized and firmly established by 2010, and for much longer described by other notions and descriptors, such as walkable, pedestrian friendly, pedestrian-oriented, and others. By 2020, one would expect we have thoroughly exhausted the scope and depth of walkability; however, returning to, dissecting, and interpreting definitions anew, we still can expand, debate, and rethink themes and principles of walkability, and apply them with new insights and clarity to our everyday living urban environments. Lately, the term has often been used to denote a measure of how walkable places are. In the present article, we would like to turn the optics around: from the walkability as a measuring tool to its potential role as a set of operational principles that can be used in urban planning and design practices to achieve more liveable and pleasant neighbourhoods.

One of the focuses of efforts towards pedestrian and cycling friendly cities is aimed at residential neighbourhoods, where we spend the majority of our time aside from work (and even those habits and attitudes have changed during the COVID-19 pandemic, as established by Rubin et al, 2020). There are two typical conditions in neighbourhoods where walkability can be observed, studied, measured, and improved, with the third as blended and proportionally various model of the first two:

a) existing residential neighbourhoods that predate explicit notions of walkability (and even sustainability), where we strive to retrofit, change, and implement the principles into an existing built environment;

b) newly designed residential neighbourhoods and city districts, where walkability principles are integrated into the initial design from the start; 
c) mixed building stock age residential districts, where existing urban fabric interchanges with newly designed building blocks in various proportions.

The present article focuses predominantly on the second - newly designed neighbourhoods and showcases themes and principles on the example of Južne Fužine neighbourhood of Ljubljana. It strives to highlight an integrative approach towards interconnected networks of walkable places, where the overall integrative effect and benefits exceed the walkability benefits of individual places.

For that purpose, the article will first look into the notion of walkability itself, its origins and later derivations, multidisciplinary perspectives, and its respective health, environmental, and economic benefits. The core of the article will then revisit- but also reinterpret - the key themes of walkability, connect them with key walkability principles, and branch them out into different items/interventions in order to make them more operational for the design and planning purposes. The above-mentioned theoretical principles will then be illustrated with envisioned, integrated implementation in a newly proposed residential neighbourhood. In conclusion, the article will sum up the different aspects discussed upon as well as assess the claim that an integrative approach should yield better results and more comprehensive, more walkable neighbourhoods than an application of principles on existing environments or retrofits in individual places.

Instead of clustering illustrations in the section in which they are referred to, the decision has been made to spread them evenly throughout the article, and thus intertwine and support the abstract notions with concrete examples of their implications and implementations on a neighbourhood level from the start. They are showcased on a newly envisioned residential neighbourhood of Južne Fužine, introduced in the second part of the article. This not only adds to the visual appeal but also stimulates the reader to constantly switch between mental and physical space, between general and particular, and between theoretical approaches and everyday life.

\section{Walkability and walkable urban environments}

The term walkable has been present for a long time and has been in use since at least the $18^{\text {th }}$ century (Internet 1, 2020), but the term walkability is more recent. It is a noun derived from adjective walkable. While European cities, built long before cars, are inherently walk-friendly (Internet 2, 2020), modernity, fast pace of city growth, and population health issues, combined with sustainability efforts, forced a rethink of how we live and move in our towns and neighbourhoods. The concept thus emerged from the most car-reliant and high obesity rates societies, and began to permeate our way of thinking about urban environments even in more pedestrian and cycling attuned localities.

Walkability is most often referred to as a measure of how favourable an environment is to walking while also providing estimates of predicted human physical activity and active travel (Wang \& Yang, 2019). Aside from being a measure, it can also be an attribute or a quality of built environment and an extent to which this environment is friendly to users who walk to their daily activities and access services on foot (Wang \& Yang, 2019). Slovenian Institute for Spatial Policies IPoP (Internet 3, 2020) defines it in similar way: walkability as a spatial attribute, the appeal of the space through which pedestrians can move easily and uninterrupted. 


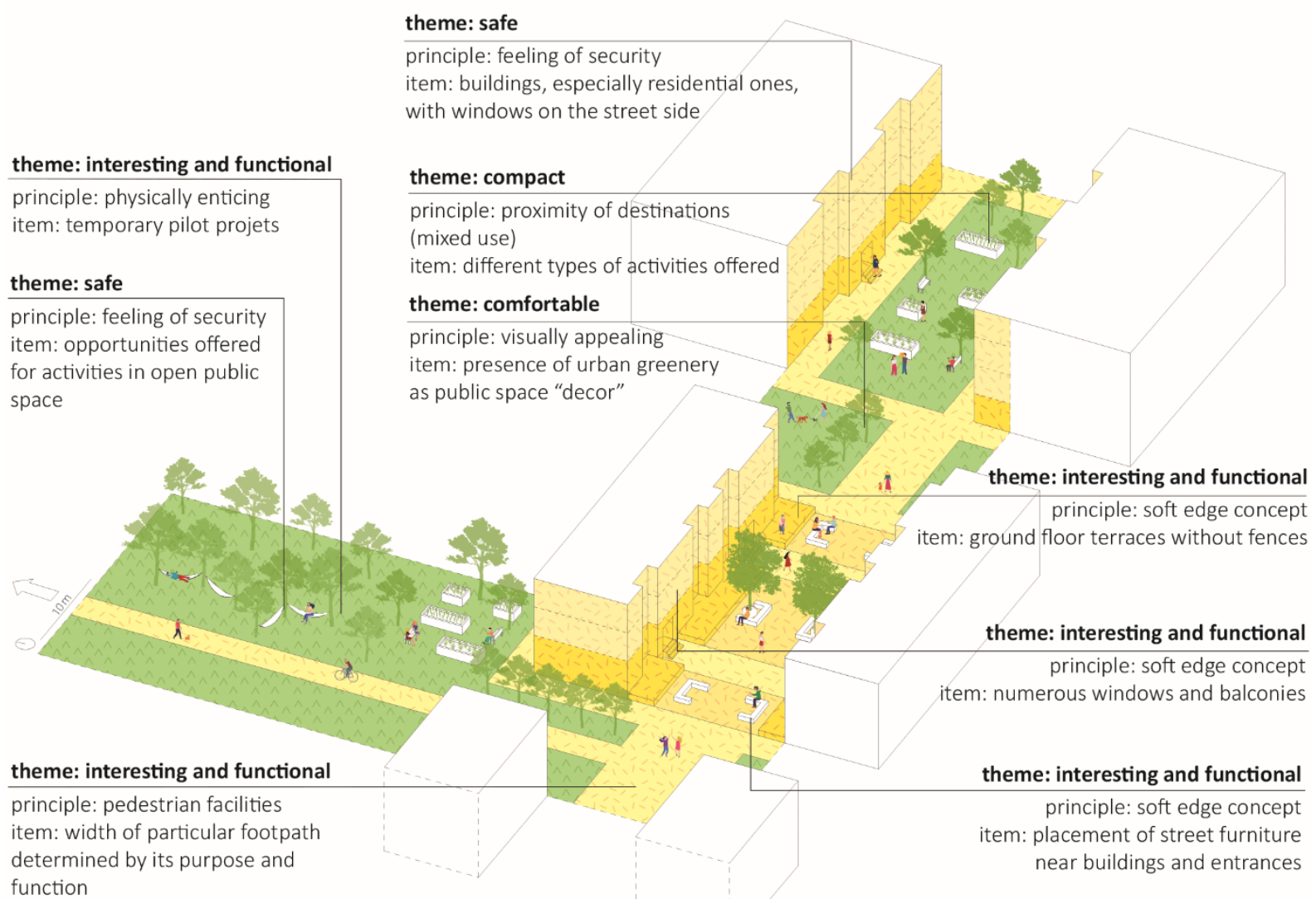

Figure 1: Neighbourhood edge where different paths start or connect the neighbourhood with other places and districts nearby - illustrations depict key walkability themes, principles, items, or interventions on a continuous path. The notions introduced and illustrated here are addressed, elaborated on, and developed throughout the article. They are showcased on a newly envisioned residential neighbourhood of Južne Fužine. (illustration: authors).

Walkability is at the forefront of debates on urban planning and the design of neighbourhoods for several reasons. It has been established that walking substantially contributes to physical and mental health of people by inducing moderate-intensity physical activity (Gebel, Bauman \& Bull, 2010). In walkability we have found the formula which re-establishes the link between our built environment and everyday physical activity. This link has been consistently broken during the industrialization age as fast transportation, fast pace of life, and fast traversing of huge distances became essential, culminating in the information age that has affixed us to spending our lives in a predominantly stationary way behind devices facilitating even faster means of communication without requiring movement on our part. As environmental attributes are related to physical activity (Gebel, Bauman \& Bull, 2010), urban designers have found additional arguments for claims that design interventions can instigate and maintain higher user activity levels.

The other, no less important reason are the findings that a walkable city promotes balanced development of urban areas and public services, offers residents better places to live, and consequently improves levels of neighbourhood satisfaction (Wang \& Yang, 2019). Walkability is increasingly becoming the measure of liveability and synonymous with good and successful design. Walkable urban environments are beneficial in many ways, on many different levels, and have a positive impact on environment, society, and economy. Walkability plays a key role in providing vital, lively, healthy, and sustainable cities. It promotes physical activity and thus 
has a positive impact on health and wellbeing of city residents. Walkable attributes are therefore not beneficial only in the field of walkability as discussed above, but are also very important for the whole concept of a city life, which is illustrated nicely by Speck (2012): "Get walkability right and much of the rest will follow.”

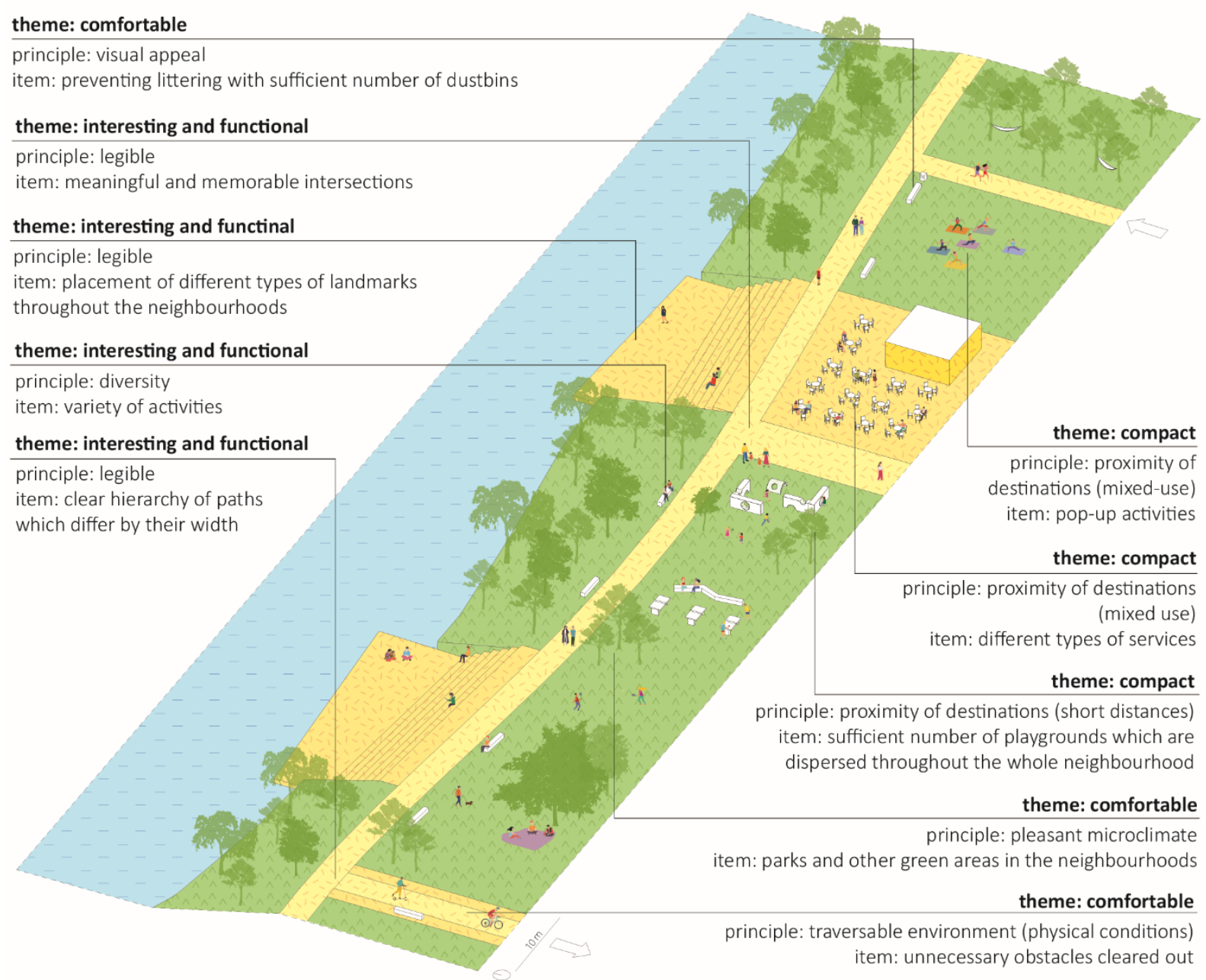

Figure 2: Green and lively riverbank in the neighbourhood with leisure and sports activities (illustration: authors).

Walkability is deemed essential by Sim (2019) since it is present in every single built relationship, every building where people live, work, and move, and can significantly contribute to sociability. According to Gehl (2010), walking is considered as a prerequisite for a lively city and the majority of social interactions. Walkable city offers people an opportunity to walk and motivates them to choose walking over some of the less sustainable means of transport. Furthermore, walkability plays a huge role in encouraging people to walk regardless of the purpose and motivates them to walk not only because they have to (goal-oriented walks) but also because they want to (walks for the sake of enjoyment and pleasure).

With association of walkable neighbourhoods with health - as well as walkable cities with overall better living conditions - walkability is surpassing its measuring role and becoming more and more a methodology of planning with a variety of design tools and initiatives leading to desired walkability goals. Its transformation from assessment and analytical tool to operational design and implementation toolbox is, however, more complex than mere reverse engineering of variables constituting walkability index. 
Research into walkable environments and neighbourhoods is at times controversial, limited, and (too) narrowly focused. Wang and Yang (2019) have pointed out that in measuring of walkability we are lacking variety of other factors, insights into the interactions between different factors, more accurate data, and use of subjective data. Additionally, the interdependence between health and built environment has not been studied across different cultures, regions, and environments, while in applications of interventions attempting to improve walkability proper verification between the intent, design, and actual increase in user's activity is absent. Beyond the objective measures of walkability there are also subjectively perceived walkability attributes among residents (Leslie et al, 2005), where researchers have found that residential density, land-use mix (access and diversity), and street connectivity add to the higher perception of walkability, while traffic safety and safety from crime did not have much impact on that perception.

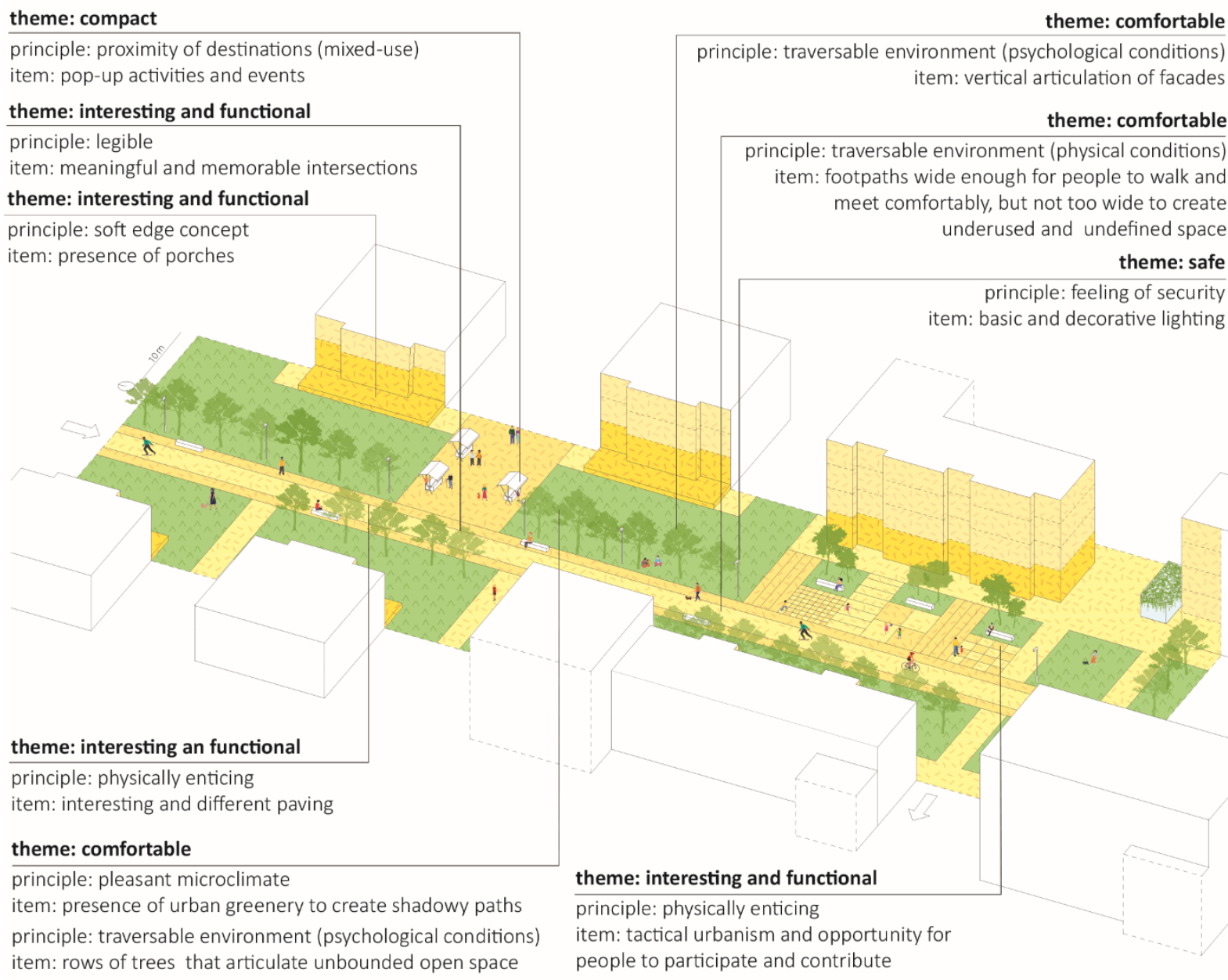

Figure 3: Central pedestrian and cycling path with various activities and interventions (illustration: authors).

Net residential density, intersection density, net retail floor area ratio, and the land use mix, most frequently used in walkability assessment (Wang \& Yang, 2019), are all macro level attributes that are not easily controlled and implemented when dealing with existing neighbourhoods and city districts. They are also hard to implement directly and need translation into urban design vocabulary at different scale levels. By adding other attributes, such as traffic conditions, aesthetics, street connectivity, or walkable distances, the problematic begins to traverse into the smaller scale, to pedestrian infrastructure, and the minute and mundane details of urban micro design, such as pavement surfaces, barrier free access, and street furniture. 
With this broader concept of walkability in mind, urban planners have found an additional source of inspiration to create environments for pedestrians that are safe, functional, comfortable, and interesting at the same time. The comprehensive notion of walkability covers a broad range and variety of different urban design concepts that can be observed from a new or different perspective of interlinked systems striving towards a common goal: walkable urban environments. Although there are many walkability concepts related either directly (e.g. curb side parking) or indirectly (e.g. policies discouraging car ownership) to urban design, we will focus on those that address urban planning and physical interventions, namely those described by Leslie et al (2005) as "concepts that address physical attributes of local environments that may influence walking” (and, one might add, other positive effects related to walkability).

In his book Walkable City (2012), Jeff Speck divides his steps into four main categories titled "The Useful Walk”, “The Safe Walk”, “The Comfortable Walk”, and “The Interesting Walk”. Every category of walkable environments includes a number of steps and, within them, many suggestions, principles, and ways to achieve them. We would like to highlight those that are most related to our focus: traffic safety, security, mixed-use, space legibility, suitable distances, green system, diversity, spatial sequences, and soft-edges.

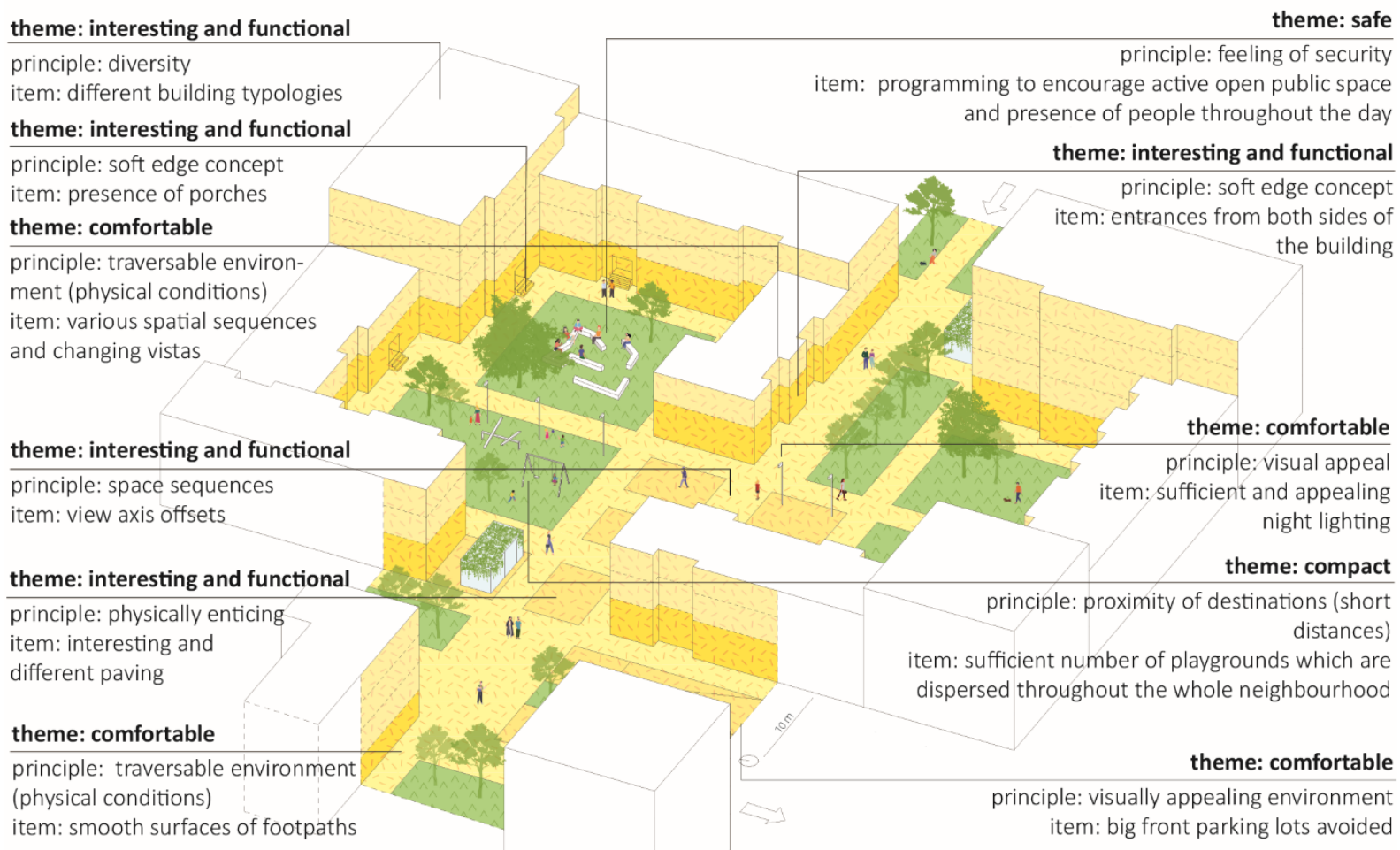

Figure 4: Semi private courtyards crisscrossed with and integrated into the network of public paths (illustration: authors).

Based on Maslow's hierarchy of needs, Mateo-Babiano (2015) derives six main pedestrian needs. The ranking of needs is based on a survey of users and the importance they ascribed to sidewalk environmental attributes. Protection and safety (1) are understandably ranked highest, with ease of use (2) and equitable access to everyone (3) trailing behind, followed by mobility (4) and identity (5), with the need for enjoyment (6) ranked last and deemed only half as important as safety. She also concedes that the ranking is not universal and might change due to demographic, individual expectations, and trip purpose (e.g. mobility would rank higher if 
our intention were to traverse the place quickly and efficiently on our way from point A to point B).

Even though we have narrowed our focus on the newly planned neighbourhoods, physical interventions and urban design, and established that users will judge the walkability experience based on their needs and purpose, we insist that there are common attributes which urban planners and designers can have direct influence on. We would like to revisit key walkability themes and principles while also illustrate implementation of principles and ways in their possible appearance in residential neighbourhood design.

While we focus on urban planners and designers, and the scope of their design interventions directly affecting spatial attributes and walkability, we are aware that comprehensive walkability can only be achieved through interdisciplinary efforts and variety of intertwined methods.

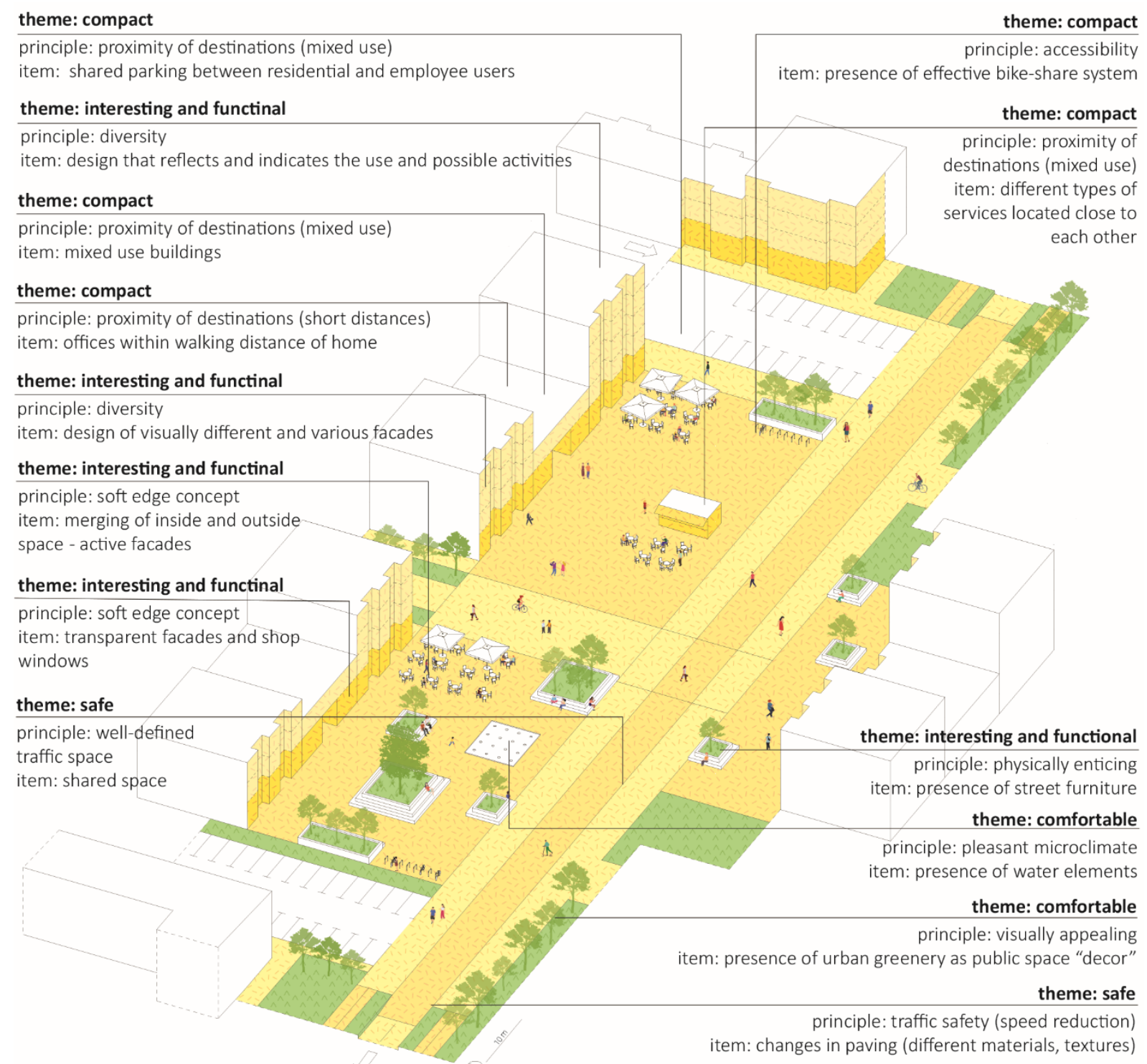

Figure 5: Central space of the neighbourhood with its multipurpose and mixed use open square (illustration: authors). 


\section{Integrated approaches and holistic walkability}

In contemporary urban design and planning field, application of walkability principles differs not only by the selection of principles and ways of their implementation but also whether they are implemented into individual, isolated environments or deliberately incorporated into the whole picture, as a series of interconnected ambiences. Newly designed neighbourhoods, such as the example in this article, lend themselves well to holistic approach, especially when it comes to physical interventions, while existing and retrofitted urban environments are not as flexible but benefit from the root communities and established social networks.

Holistic approach in planning and designing of walkable cities and neighbourhoods is becoming essential since it is the only way urban designers can design open public spaces that are well connected and offer pedestrians unique, continuous, and narrative spatial experience. The integrative approach is extensive and more demanding in nature yet more effective in comparison to individual small-scale projects that are often designed in isolation or with limited possibilities of connecting to already established, built up surrounding places.

While Forsythe (2015) takes holistic solution as one of the proxy definitions for defining better environments that generate investment, are more sustainable, and are in general better places to be in, we would like to take the integrative and holistic design approach further, arguing that it is not only a proxy indicator of walkability, an outcome, but rather a means to an end and a planning instrument towards better walkability outcomes. By planning walkability experiences in integrative fashion, as a series of interconnected and continuous places and space flows, we can achieve better and more holistic results. 


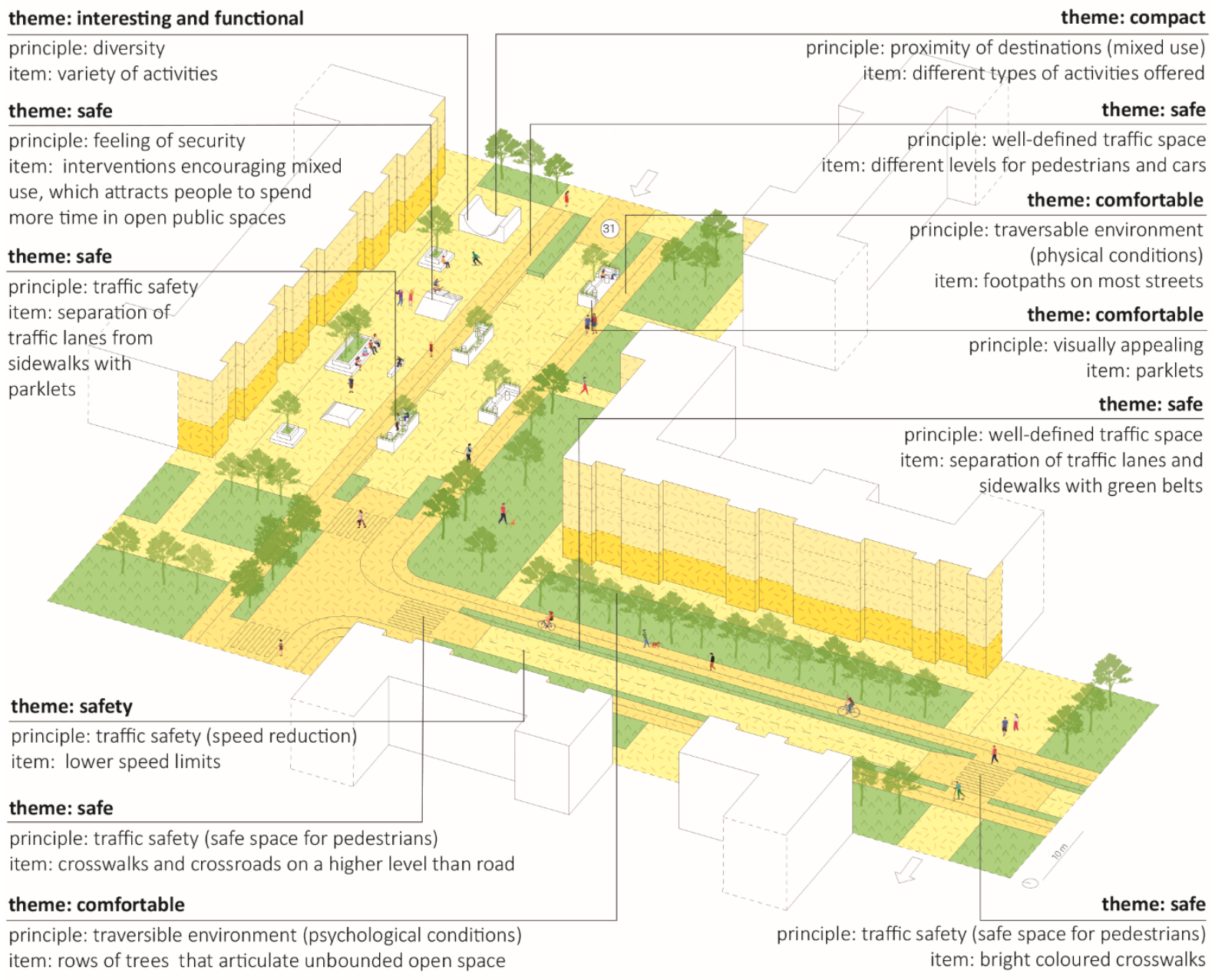

Figure 6: Common streets in residential neighbourhood with walkability principles applied (illustration: authors).

As pedestrians, our interaction with urban environments is predominantly experiential. This is significant because such an experience is common to all of human beings, regardless of age, status, and interests. It is based on our sensory apparatus and perception (and also limited by it, e.g. vision, field of view), on our exploration by moving, relative scales and estimations rather than factual measurements, first person perspective, and intuition. Cullen (1961) sums it up with his notion of serial vision and continues to establish the user's relative positioning in regards to the places she moves through (outside, entering, being in the middle, leaving, etc.). The design of such places has to adapt to these findings; by following them, it is in essence democratizing the experience to all users and user groups.

\section{Revisit and reinterpretation of key themes}

As introduced above, the notion of walkability consists of many interconnected principles which, when implemented deliberately and consistently, provide safe, useful, comfortable, interesting, and therefore walkable network of open spaces, well integrated into the core of a neighbourhood design. Forsyth (2015) separates key themes or dimensions of walkability (from here on referred to as walkability themes or key themes) into three clusters of attributes: means (traversable, compact, safe, and physically enchanting), outcomes (lively and sociable, sustainable transportation options, exercise including), and proxies (measureable, holistic solution). All of the above-mentioned are interconnected; they all contribute to walkable places, 
but not all of them are always present at the same time - or at the same level - and they also differ depending on the specific environment.

For the purpose of our article, we have derived our walkability principles and their definitions from Forsyth's (2015) themes, modified them, combined them with Speck's (2012) categories of walkability, and diversified them by selected derivations of steps turned into principles from "Walkable city rules" (Speck, 2018). We have also extended them with contributions from other researchers in the field (Leslie et al, 2005; Sulaiman, 2020; Wang \& Yang, 2019; Saelens, Sallis \& Frank, 2003; Cerin et al, 2006; Leyden, 2003; Gehl, 1971 and 2010; Sim, 2019). By doing so, we have broadened the scope and systematics of notions in order to cover full variety of walkability attributes under urban designer's scope of interventions. Each key theme of walkability (Forsyth, 2015) is revisited and examined first, followed by re-think of the implications on urban design practices, and suggestions for widening of particular notions offered as well as renaming of the others for clarity purposes or to introduce new, extended meaning.

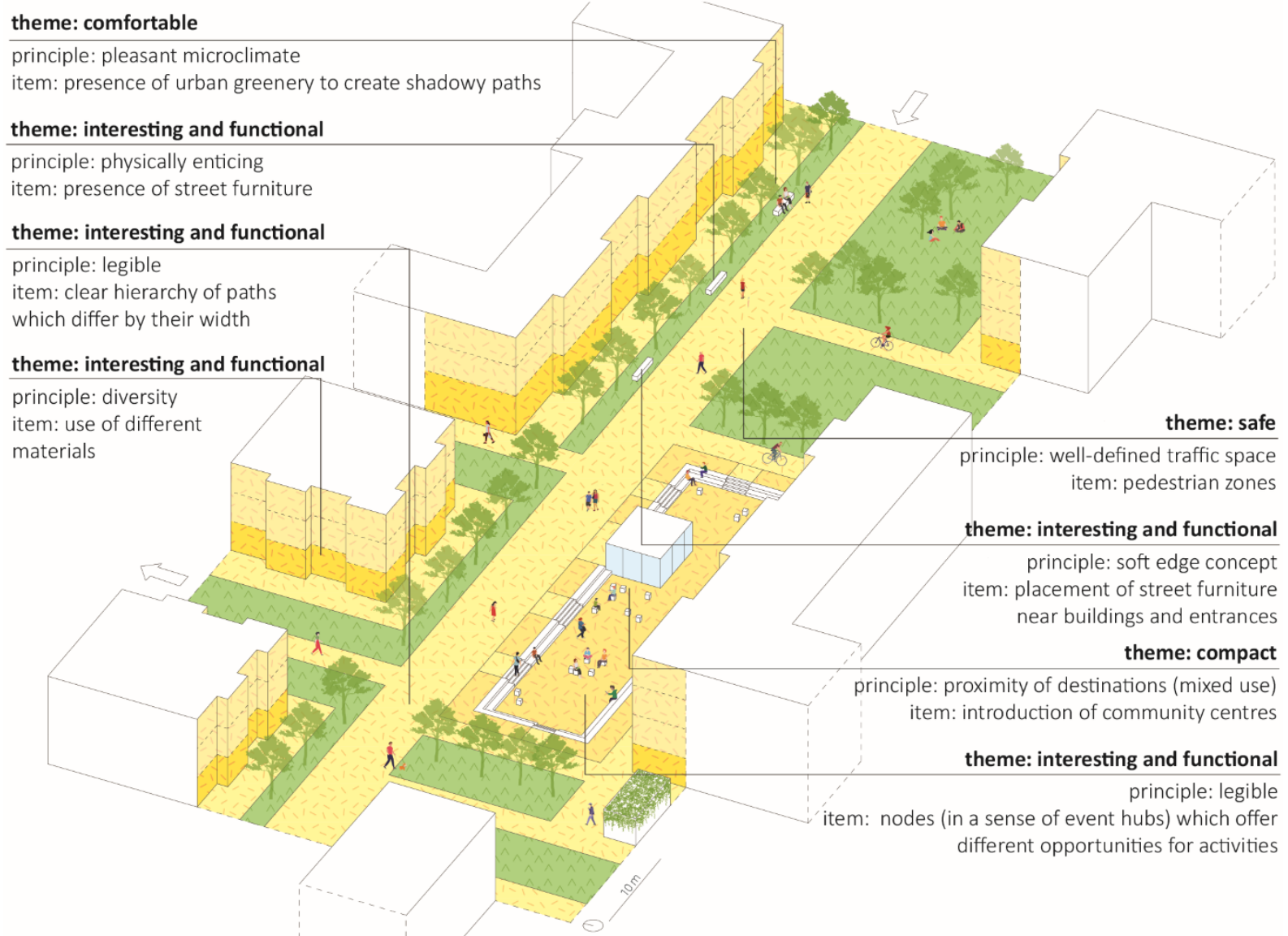

Figure 7: Public square with a distinctive design - open space as a landmark (illustration: authors).

The themes inside the cluster of means will be observed first. According to Forsyth (2015), "traversable environments have the basic physical conditions to allow people to get from one place to another without major impediments, for example, relatively smooth paths". Traversable is a walkability aspect, which falls into a category of comfort, alongside urban greenery and many other design principles that make space appealing and comfortable to walk through. We suggest the term "comfortable", because it both covers traversability as introduced by Forsyth and widens its meaning by adding additional qualities beyond mere utilitarian, including different groups and levels of comfortability of traversing. 
For Forsyth (2015), compact places provide short distances to destinations for those who are walking for utility. The term compact covers the already introduced principle of proximity and short distances between everyday destinations. This Forsyth's theme therefore falls into the aforementioned category of usefulness of the space but is concrete and intelligible in terms of urban design. In comparison to our term useful, it does not cover the principle of legibility of the space but covers the principle of mixed use. We have kept the term "compact", which will in our case include both proximity and mixed-use but exclude legibility of the space, which we will discuss later on.

Forsyth (2015) states that safe spaces should be understood as "places being safe for walking perceived and actual crime and perceived and actual traffic safety". The denoted meaning of "safe" is aligned with definitions from our introduction, which include walkability principles for achieving traffic safety and general feeling of security.

For Forsyth (2015), physically-enticing environments "have full pedestrian facilities such as sidewalks or paths, marked pedestrian crossings, appropriate lighting and street furniture, useful signage, and street trees. They may also include interesting architecture, pleasant views, and abundant services attractive to those who have other choices for getting around and getting exercise.” Forsyth's definition of the term is very broad; it covers many different aspects of physical qualities of the space. It includes some principles that could easily fall into other themes. For example, sufficient lightning and pedestrian facilities are more suitable for category safe; trees on streets have already been mentioned in category comfortable; and service attractiveness and diversity has already been considered in the compact category.

As many of those principles overlap, and are interconnected and interdependent, we have decided to retain them and change the naming from "physically-enticing" to "interesting and functional", which caters to Forsyth's definition and at the same time adds some of the following principles: legibility of the space, variety of built and open space morphology, concept of space sequences and soft-edge principles.

Under the cluster of outcomes dwells the theme lively and sociable (places), which are pleasant, clean, and full of interesting people, according to Forsyth (2015). Likewise, Gehl (2010) emphasizes the importance of walking and describes it as one of the prerequisites for a lively and sociable city. We agree with the poetic definition which denotes these characteristics well and is aligned with our and common understanding of these notions in their broader socioeconomic meaning. When it comes to sustainable transportation options, we suggest broader term sustainable (in general) that goes beyond Forsyth's (2015) transport focused understanding of walkability "as a way to achieve both the environmental preservation and social equity components of sustainable urban form providing sustainable transportation options". As well as sustainable transportation options, sustainable in general covers some additional outcomes, such as sustainable aspects of microclimate design and control, energy efficiency, sustainable design and maintenance practices, etc.

For Forsyth's (2015) health focused exercise-inducing, where she sees benefits in "higher than average levels of walking either in total or for transportation or exercise", we suggest broader term "inviting to move on foot" that covers both the idea of inducing exercise and the concept of choosing walking over some other, less sustainable, transportation options. This theme therefore covers a wide range of health benefits for space users and city residents, but it also alludes to spaces that invite people to walk (and cycle) and encourage them to do so, not only for health benefits but also because it is more practical, less time consuming for short distances, provides more experiences and sensorial inputs, promises more social interaction, is less tedious 
and more fun than, for instance, driving a car. Some of these qualities are already reflected through both above-mentioned outcomes (lively, sociable and sustainable); however, we decided that "inviting to move on foot" is a defining quality or outcome that deserves to be singled out.

Forsyth's (2015) proxy definitions are complex and, as she states, draw together elements of prior themes. We agree with the complexity that multidimensionality and holistic solutions bring into the equation of walkability and are thus taking over the proposed definitions. However, due to their broadness and derivative nature of previous themes (notions), we abstain from addressing them in our case study and rather use them for summary of before mentioned topics and principles. Nevertheless, we also single out holistic solutions as a means in an integrative approach, especially in the design of new districts and neighbourhoods, where the holistic integration into the initial design brings many benefits over later retrofits.

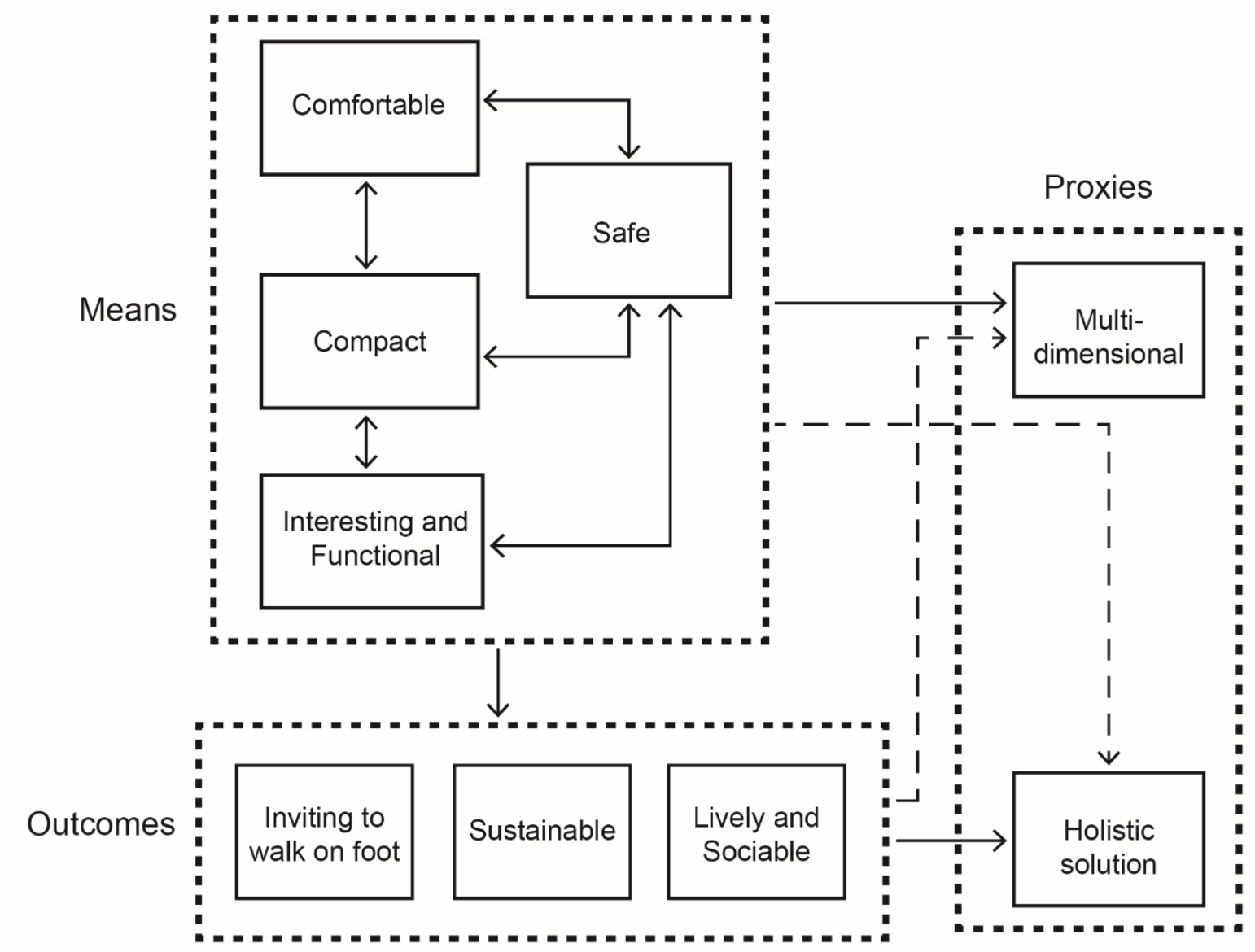

Figure 8: Linking modified key themes of walkability into an existing scheme (initially proposed by Forsyth, 2015; and modified by the authors).

To sum up, we agree with Forsyth's (2015) definitions to a wide extent; however, we felt the need to broaden some of them, include additional aspects which we deemed important, and at some instances rename them in a more obvious fashion. 


\section{Key Themes Translated into Key Urban Design Principles and Items}

To make the key walkability themes operational for urban planning and design purposes, we have systematically translated and concretized them in the tables (Table 1-4) and, additionally, visualized them on a neighbourhood scale proposal.

Table 1: Addressing key principles, items, and interventions within the key walkability theme - Comfortable

\begin{tabular}{|c|c|c|}
\hline \multicolumn{2}{|c|}{ Walkability principles } & Items / interventions \\
\hline & $\begin{array}{l}\text { traversable environment } \\
\text { - } \\
\text { physical conditions } \\
\text { concerning footpath and } \\
\text { road design } \\
\text { - } \text { psychological } \\
\text { conditions concerning } \\
\text { interventions that } \\
\text { encourage people to } \\
\text { walk and make their } \\
\text { walking experience } \\
\text { more pleasant, } \\
\text { especially the concept of } \\
\text { actual and perceived } \\
\text { distance }\end{array}$ & $\begin{array}{ll} & \text { regarding physical conditions: } \\
\text { - } & \text { footpaths on most streets } \\
\text { - } & \text { footpaths well maintained } \\
\text { - } & \text { smooth surfaces of footpaths } \\
\text { - } & \text { same level paths or at least minimal interruptions regarding level of } \\
& \text { paths } \\
\text { - } & \text { unnecessary obstacles cleared out } \\
\text { - } & \text { footpaths wide enough for people to walk and meet comfortably, but } \\
\text { not too wide to create underused and undefined space } \\
\text { - } \quad \text { amount of space dedicated to motorized traffic reduced } \\
\text { - } \text { limits to motorized traffic lanes width and width reserved for side } \\
\text { parking (e.g. MOL, 2012) } \\
\text { - } \quad \text { optimized driving network in a way that does not have a negative } \\
\text { impact on pedestrians } \\
\text { - } \text { porous driving network instead of branching network }\end{array}$ \\
\hline b) & $\begin{array}{l}\text { visually appealing } \\
\text { environment }\end{array}$ & $\begin{array}{l}\text { - lead pedestrian intervals on semaphorized crossroads } \\
\text { regarding psychological conditions: } \\
\text { - } \text { various spatial sequences and changing vistas }\end{array}$ \\
\hline c) & $\begin{array}{l}\text { pleasant microclimate } \\
\text { achieved both with urban } \\
\text { planning and landscape } \\
\text { architecture interventions }\end{array}$ & $\begin{array}{l}\text { - } \quad \text { tiring one-point perspective avoided where possible } \\
\text { - } \quad \text { vertical articulation of facades } \\
\text { - } \text { rows of trees that articulate unbounded open space } \\
\text { regarding visual appeal: } \\
\text { - } \text { preventing littering with sufficient number of dustbins } \\
\text { - } \text { presence of urban greenery as public space “decor” } \\
\text { - } \text { presence of green areas in the neighbourhoods } \\
\text { - } \quad \text { big front parking lots avoided } \\
\text { - } \quad \text { sufficient and appealing night lightning } \\
\text { - } \quad \text { parklets } \\
\text { - } \text { regarding pleasant microclimate: } \\
\text { - } \text { presence of urban greenery to create shadowy paths } \\
\text { neighbourhood design } \\
\text { - } \text { presence of water elements } \\
\text { - } \text { parks and other green areas in the neighbourhoods }\end{array}$ \\
\hline
\end{tabular}

Key principles are derived from the themes, and address graspable and physically implementable walkability principles, especially in the means category, which we see as an urban designer's intervention toolbox of ideas, solutions, and inspirations. Since research has established correlations between environment characteristics and walkability in the domains of residential density, land use mix-diversity and land use mix-access, street connectivity, walking/cycling facilities, aesthetics, traffic and crime safety, we have examined sample items from Neighbourhood Environment Walkability Scale (Saelens et al, 2003) from the aspect of their intervention "capital”. The items have been used to calculate - or measure through surveys - the walkability index. Looking at them from the designer's perspective, we see opportunities for deliberate targeting of some of these items with interventions in order to intentionally - and through design - directly influence the walkability outcomes. 
Table 2: Addressing key principles, items, and interventions within the key walkability theme - Compact

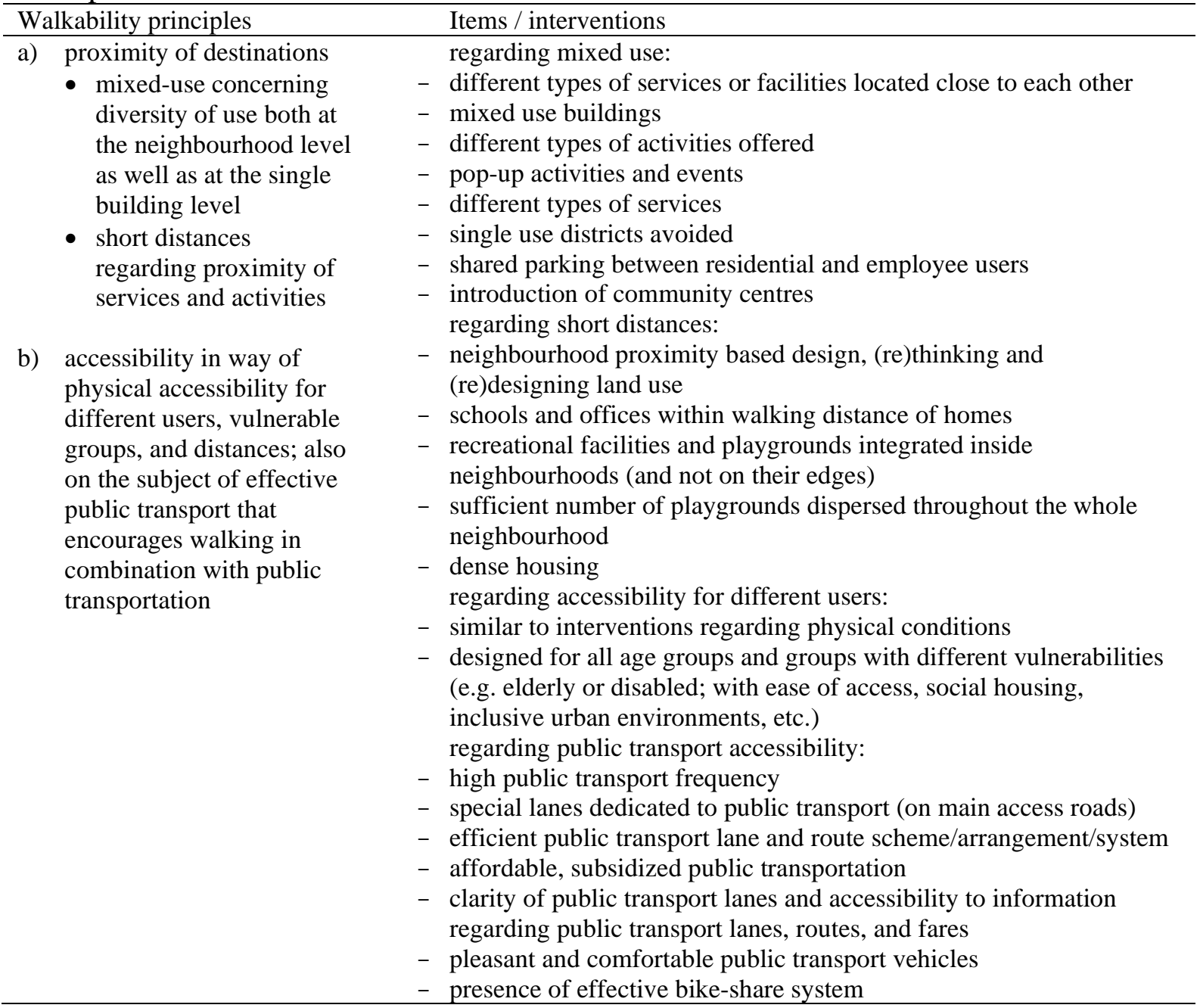

Items have thus been selectively derived not only from research (Saelens et al, 2003) but also reformulated from Speck's (2018) rules, Gehl's (2010) principles and amalgamated with other means that target design interventions and environmental characteristics established to correlate with walkable environments (from research listed in the previous subchapter). As underlined in the introduction, we are observing newly designed residential neighbourhoods and districts, not retrofits. 
Table 3: Addressing key principles, items, and interventions within the key walkability theme - Safe

\begin{tabular}{|c|c|c|}
\hline & lkability principles & Items / interventions \\
\hline & $\begin{array}{l}\text { traffic safety } \\
\text { - } \text { motorized traffic speed } \\
\text { reduction } \\
\text { - safe space for } \\
\text { pedestrians in areas } \\
\text { where motorized and } \\
\text { non-motorized traffic } \\
\text { intertwine } \\
\text { - well-defined traffic } \\
\text { space that can be done } \\
\text { in two different - } \\
\text { mutually opposite - } \\
\text { ways: deliberately } \\
\text { merging different traffic } \\
\text { spaces into one whole } \\
\text { (shared space) or } \\
\text { hierarchically dividing } \\
\text { them into subcategories } \\
\text { of more conventional } \\
\text { traffic spaces }\end{array}$ & 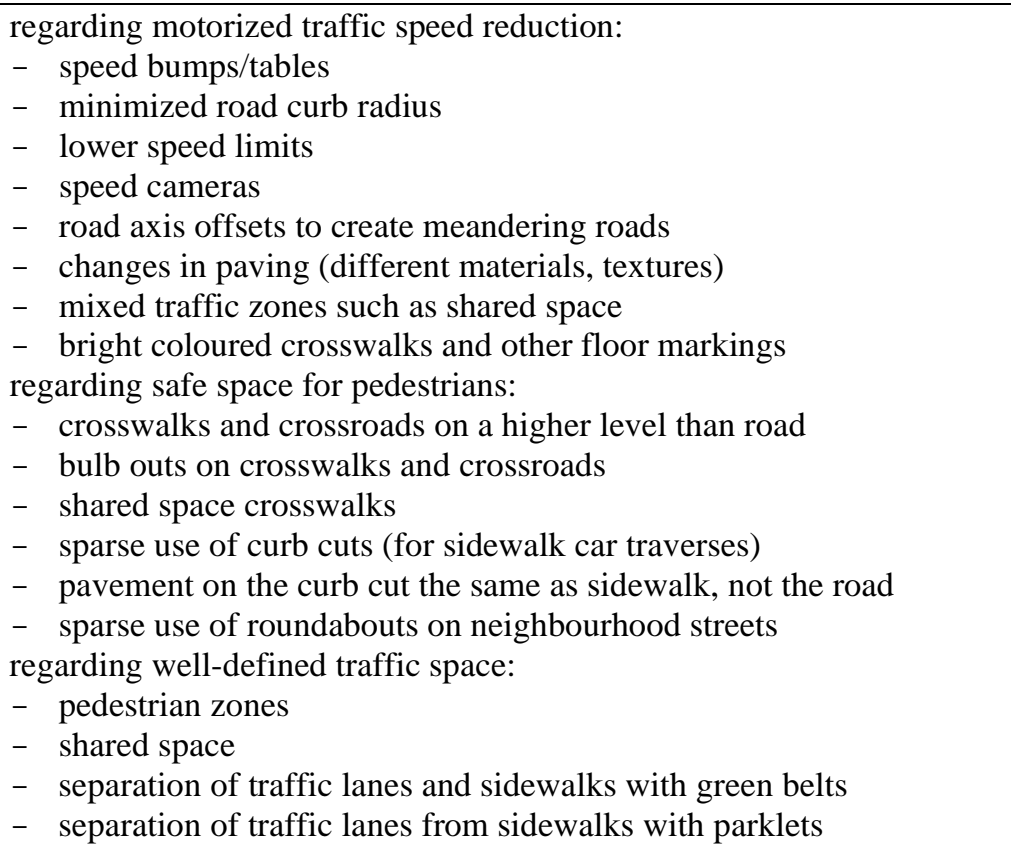 \\
\hline b) & $\begin{array}{l}\text { feeling of security that } \\
\text { mostly originates from } \\
\text { human presence in the } \\
\text { space and overall design of } \\
\text { open spaces }\end{array}$ & $\begin{array}{l}\text { - } \text { trees planted on road curbs } \\
\text { - } \quad \text { use of legible and well-visible traffic signalization, both horizontal } \\
\text { and vertical } \\
\text { - } \quad \text { different levels for pedestrians and cars } \\
\text { regarding feeling of security: } \\
\text { - } \quad \text { buildings, especially residential ones, with windows on the street } \\
\text { side } \\
\text { - } \quad \text { interventions encouraging mixed use, which attracts people to spend } \\
\text { more time in open public spaces } \\
\text { - } \quad \text { opportunities offered for activities in open public space } \\
\text { - } \quad \text { programming to encourage active open public space and presence of } \\
\text { people throughout the day } \\
\text { - basic and decorative lighting }\end{array}$ \\
\hline
\end{tabular}

Tables 1, 2, 3, and 4 parallel principles and items within each key walkability theme, establishing a hierarchical connection from overarching and more abstract themes through more specific principles to operational physical interventions in the hands of urban planners and designers. 
Table 4: Addressing key principles, items, and interventions within the key walkability theme - Interesting and Functional

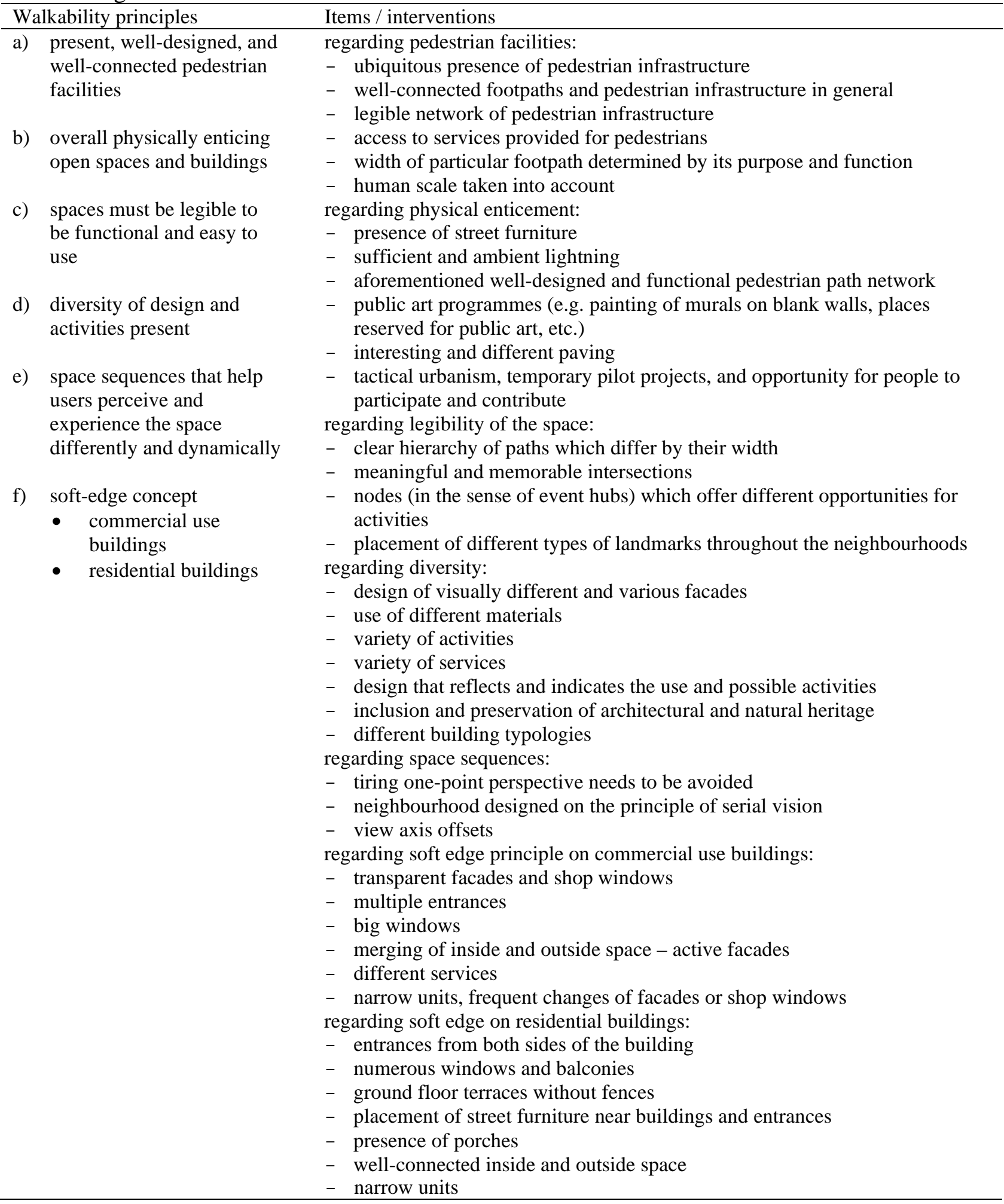

The majority of themes, principles and interventions from Table 1-4 are depicted throughout Figures 1-8 which follow an everyday path from home to school in a newly designed neighbourhood of Južne Fužine. The neighbourhood, which has been envisioned for a bachelor's thesis project (Žnidaršič, 2020), is located on the eastern edge of Ljubljana in the immediate vicinity of the highway ring and the Ljubljanica River at the junction of urban and 
rural spatial context. The new residential district covers 35ha and includes residential, educational, commercial, and mixed use buildings, which vary in typology, morphological structure, and height. Four main two-way streets are shared with motorized traffic, while all other paths and areas in the neighbourhood are designed for pedestrians and cyclists only. Among the central features are "green" footpaths connecting larger green spaces adjacent to the district in the south, and the riverbank in the north.

Although out of many possible alternatives a specific path has been selected and illustrated for the reason that it crosses the greatest variety of places, it is representative in terms of a holistic approach and integrated walkability implemented throughout the entire neighbourhood. The illustrations demonstrate opportunities and potential compatibility of interventions and items when they occur in various combinations and where their combined effect is larger than their individual sum. Thematically we are following a sequence of spaces starting at the neighbourhood edge (Figure 1) where we encounter mostly principles and interventions within themes that are interesting and functional as well as comfortable. Riverbank (Figure 2) introduces items regarding visual appeal, diversity, and proximity of destinations. Central pedestrian and cycling path (Figure 3) with various activities and interventions is one of the backbones of the walkable neighbourhood where principles of traversable environment and overall interesting and functional theme are dominating. Semi-private courtyards crisscrossed with and integrated into the network of public paths (Figure 4) illustrate the theme safe, principles regarding physical enticement, diversity, and soft edge. Central space of the neighbourhood (Figure 5) is the heart of the multipurpose and mixed use demonstrating compactness and other themes. Common street (Figure 6) is a representative of the typical residential and walkable street in the neighbourhood where principles of traffic safety and feeling of security are present. Public square with distinctive design (Figure 7) represents an open space as a landmark approach where items regarding legibility, visual appeal, and physical enticement come into play. Educational facilities in the neighbourhood and their immediate surroundings (Figure 9) illustrate principles regarding items of comfort along with principle instigating interesting and functional places.

\section{Discussion and conclusion}

The present article set out to examine broader theoretical scope of walkability and research efforts dealing with measurement of walkable environments, with the specific aim to distil and translate walkability as a measure into walkability as a design principles toolbox. The reasoning behind the shift of the perspective is based on the findings of various researchers who found positive correlation between physical attributes of local environment and increase of users walking or cycling and other positive effects related to walkability. By directly influencing - in urban planning and design terms, by deliberately designing and changing our local living environments - we can improve the walkability of our neighbourhoods.

Overarching walkability themes which can be clearly divided into three main categories - how we set to achieve walkable environments (means); what we can expect from walkable environments (outcomes); and by which other scales we can evaluate or think about them (proxies) - are excellent starting points. Nonetheless, planners and designers need to translate abstract notions into liveable and tangible urban environments. For this reason, the walkability themes have been branched out into more concrete walkability principles and these in turn expanded into physically implementable items and interventions. With this in place, we now have a complete design and examination cycle of interventions leading to more and better 
walkable environments, with research efforts able to investigate and provide new insights and new suggestions disseminating back into the design loop at different levels (items/interventions, principles or/and themes).

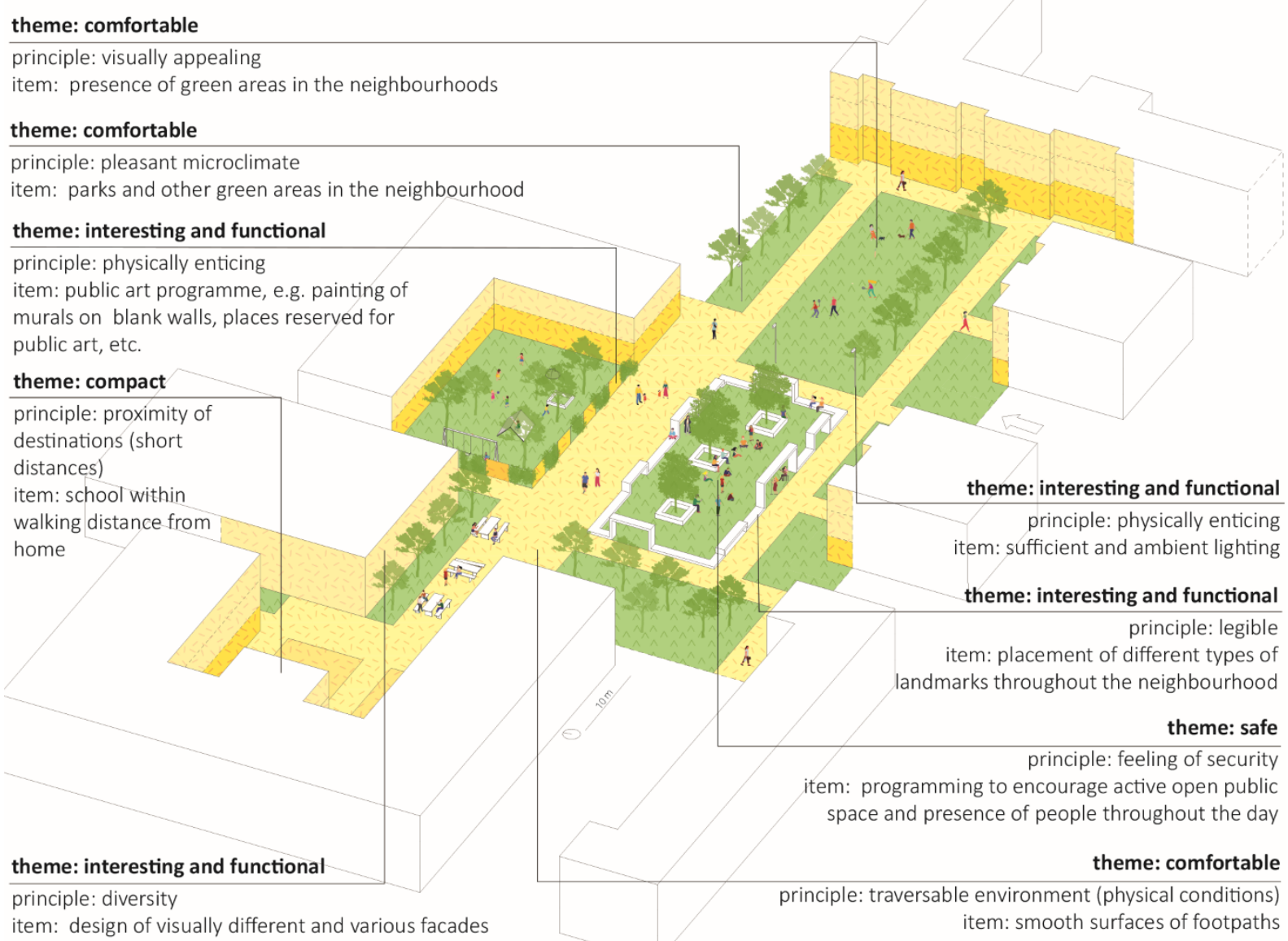

Figure 9: Educational facilities in the neighbourhood and their immediate surroundings

With the idea of broadening and branching out of themes towards the bottom-up design interventions in mind, we wanted to address the topic of walkability in general, deepen the understanding of its complexity, and Europeanize it - observe it from the perspective of European urban contexts and realities which are markedly different from cultural and urban contexts on other continents.

We have focused predominantly on physical interventions within reach of urban designers and urban planners - the means category - yet in doing so we have by no means exhausted all other means, such as policy changes strategies, changes of attitudes, changes of habits, economic incentives, and other non-physical, initiative based approaches. They remain powerful means to support and enhance the proposed physical interventions.

While a significant number of items and interventions included could find a place and improve walkability in existing neighbourhoods, we have addressed and highlighted the scope of possibilities in newly designed residential neighbourhoods, leaving out some important interventions and principles that would also benefit walkability in existing urban environments (e.g. renewal and maintenance of cultural and natural heritage, changes in existing traffic networks and flows, etc.). 
Equally, the article has an applicable and professional side. Interventions and items in the tables can be understood and used as a palette of tools available to urban designers to achieve walkable, lively environments. They are depicted and shown on site with the descriptors explaining the theme they belong to, principle they address, and interventions themselves in an understandable narrative and integrated fashion. Although the illustrations come from the design of a specific neighbourhood, the spaces depicted are common enough to be used as inspiration for numerous situations with similar opportunities.

As already stated throughout the article, walkability themes - and especially principles - are interconnected, interdependent, and in many ways affect each other. Due to the overlaps, it was therefore sometimes challenging to divide them into groups as some principles fit into more than one theme.

Speck (2018: 12) claims that "people will not walk unless the walk serves some purpose”. Aside from purpose, which provides the reason for walking or cycling activity, they will base their decisions on other factors as well, such as convenience of choosing this mode of transport over others, the appeal of the activity itself, the appeal of the environment they will be moving through, and the amount of effort and time they will need to invest in the activity. The benefits will usually outweigh the investment of effort and time only if the main activity of walking to an errand or a service or for leisure promises the potential of other side benefits and pleasurable activities that might occur during the walk, such as socializing, window shopping, exercising, playing, or moving through pleasant, well maintained, well equipped, convenient, interesting, and engaging environment.

And at this point we return to one of our initial claims that such urban environments will only emerge with holistic and integrated approach and design to walkable neighbourhoods, where such a flow of interconnected interventions, spatial attributes, and incentives has been established as will result in higher walkability, both as perceived among the users as well as objectively measured. The holistic aspects of walkability - dealing with all of them at once and its multidimensionality - intertwinement and co-dependency - are its integral parts in design, implementation and evaluation. The present article thus not only derives and lists the interventions but also demonstrates them in one of such integrated approaches that illustrates a potential walking path to an everyday errand - such as walking to school or walking to a shop - where the neighbourhood design favours walking and cycling over other means of transport and where these two and other activities promise a more pleasurable, social, and fulfilling experience.

\title{
Kaja Žnidaršič, Ljubljana, Slovenia (kaja.znidarsic@gmail.com)
}

\author{
Matevž Juvančič, University of Ljubljana, Faculty of Architecture, Slovenia \\ (matevz.juvancic@fa.uni-lj.si)
}

\section{Acknowledgements}

The theoretical part of the article has been revised and expanded from the conference contribution (Juvančič \& Žnidaršič, 2020) presented at and published in City Street4 (CS4): Streets for 2030, Ljubljana, 23-24 September 2020. 
The main theme was completely refocused and reworked with an emphasis on residential neighbourhood and demonstration of themes, principles, and interventions that are supported by extensive depictions not present in the previous publication.

The research discussed in the article is partially supported by the Slovenian Research Agency within the framework of P5-0068 Sustainable Planning for Quality Living Space.

\section{References}

Cerin, E., Saelens, B. E., Sallis, J. F. \& Frank, L. D. (2006) Neighborhood environment walkability scale: Validity and development of a short form. Medicine \& Science in Sports \& Exercise, 38(9), pp. 16821691. DOI: 10.1249/01.mss.0000227639.83607.4d

Cullen, G. (1961) The concise townscape. London, Architectural Press.

Forsyth, A. (2015) What is a walkable place? The walkability debate in urban design. Urban Design International, 20(4), pp. 274-292. DOI: 10.1057/udi.2015.22

Gebel, K., Bauman, A. E. \& Bull, F. C. (2010) Built environment: Walkability of neighbourhoods. Evidencebased public health: effectiveness and efficiency, 1(1), pp. 298-312. DOI: 10.1093/acprof:oso/9780199563623.003.019

Gehl, J. (1971) Life between buildings. Washington D.C., Island Press.

Gehl, J. (2010) Cities for people. Washington D.C., Island Press.

Internet 1: https://www.merriam-webster.com/dictionary/walkable (accessed 24 Nov. 2020).

Internet 2: https://www.jll.pe/en/trends-and-insights/cities/why-cities-are-bringing-walking-into-focus (accessed 9 Aug. 2020).

Internet 3: https://ipop.si/urejanje-prostora/izrazje/hodljivost/ (accessed 25 July 2020).

Juvančič, M. \& Žnidaršič, K. (2020) Walkability themes and principles examined on Ljubljana city centre and Južne Fužine neighbourhood. In: Fikfak, A. et al. (eds.): City Street 4: Streets for 2030: proposing streets for integrated and universal mobility. Book of proceedings: Ljubljana, 23-24 September 2020, pp. 342361. Ljubljana, Faculty of Architecture and Urban Planning Institute of the Republic of Slovenia.

Leslie, E., Saelens, B., Frank, L., Owen, N., Bauman, A., Coffee, N. \& Hugo, G. (2005) Residents' perceptions of walkability attributes in objectively different neighbourhoods: A pilot study. Health and Place, 11(3), pp. 227-236. DOI: 10.1016/j.healthplace.2004.05.005

Leyden, K.M. (2003) Social capital and the built environment: The importance of walkable neighborhoods. Am J Public Health, 93(9), pp. 1546-1551. DOI: 10.2105/ajph.93.9.1546

Mestna občina Ljubljana (2012) Navodila za načrtovanje prometnih ureditev v MOL. Ljubljana.

Mateo-Babiano, I. (2016) Pedestrian needs matter: Examining Manila's walking environment. Transport Policy, 45, pp. 107-115. DOI: 10.1016/j.tranpol.2015.09.008

Rubin, O., Nikolaeva, A., Nello-Deakin, S. \& te Brömmelstroet, M. (2020) What can we learn from the COVID-19 pandemic about how people experience working from home and commuting? Research report. Amsterdam, Centre for Urban Studies, University of Amsterdam.

Saelens, B. E., Sallis, J. F. \& Frank, L. D. (2003) Environmental correlates of walking and cycling: Findings from the transportation, urban design, and planning literatures. Annals of Behavioral Medicine, 25(2), pp. 80-91. DOI: 10.1207/S15324796ABM2502_03

Sim, D. (2019) Soft city: Building density for everyday life. Washington D.C., Island Press. Speck, J. (2012) Walkable city. New York, North Point Press.

Speck, J. (2018) Walkable city rules: 101 steps to making better places. Washington D.C., Island Press.

Sulaiman, I. M. (2020) Walkability in different contexts in neighbourhood planning: An overview. Architecture Research, 10(1), pp. 27-43. DOI: 10.5822/978-1-61091-899-2

Wang, H. \& Yang, Y. (2019) Neighbourhood walkability: A review and bibliometric analysis. Cities, 93, pp. 43-61. DOI: 10.1016/j.cities.2019.04.015

Žnidaršič, K. (2020) Principi hodljivosti v urbanih soseskah: študija na primeru soseske Južne Fužine. Unpublished diploma thesis. Ljubljana, University of Ljubljana, Faculty of architecture. 